\title{
Electro-optical properties, decomposition pathways and the hydrostatic pressure-dependent behaviours of a double-cation hydrogen storage material of $\mathrm{Al}_{3} \mathrm{Li}_{4}\left(\mathrm{BH}_{4}\right)_{13}$
}

\author{
MEHMET ŞIMŞEK \\ Department of Physics, Faculty of Sciences, Gazi University, 06500 Teknikokullar, Ankara, Turkey \\ msimsek@gazi.edu.tr
}

MS received 29 April 2015; accepted 10 January 2017; published online 16 August 2017

\begin{abstract}
Electro-optical properties, the decomposition pathways and the pressure-dependent behaviours of $\mathrm{Al}_{3} \mathrm{Li}_{4}\left(\mathrm{BH}_{4}\right)_{13}$ have been investigated using a first-principle plane-wave pseudopotential method. $\mathrm{Al}_{3} \mathrm{Li}_{4}\left(\mathrm{BH}_{4}\right)_{13}$ is a kind of double-cation borohydride, consisting of distorted tetrahedral anions $\left[\mathrm{Al}\left(\mathrm{BH}_{4}\right)_{4}\right]^{-}$and cations $\left[\mathrm{Li}_{4}\left(\mathrm{BH}_{4}\right)\right]^{3+}$, which obeys the stability criteria of decomposition reactions. Herein, two possible decomposition reactions of the compound are proposed, which release 18 hydrogen molecules (about $12.03 \mathrm{wt} \%$ ) in the first reaction and 24 hydrogen molecules (about $16.04 \mathrm{wt} \%)$ in the second reaction. On increasing the pressure on the structure, the lattice parameter, the volume of unit cell, the quasiparticle band gap and also enthalpy of the system decrease nearly monotonically; therefore, the acceptor levels gradually get filled and the Fermi level shifts upward. Results of computational investigations of the structural, electronic and thermodynamic parameters and their pressure-dependent behaviours indicate that $\mathrm{Al}_{3} \mathrm{Li}_{4}\left(\mathrm{BH}_{4}\right)_{13}$ has intriguing properties. Therefore, it would be a very promising material for hydrogen storage technology.
\end{abstract}

Keywords. First-principle calculations; hydrogen storage materials; high pressure; photon excitation properties; bimetallic borohydrides.

\section{Introduction}

Fossil fuels provide the main source of energy for our today's global economy; everybody knows that stocks of fossil fuels are limited and alternatives need to be found. Hydrogen is one of the alternative energy sources, which has most remarkable properties such as being the most abundant element in the universe and also an environment friendly renewable energy carrier [1-4]. We know that today's hydrogen energy technology is still limited and it needs significant progress [5] to overcome the many storage problems for safe mobile applications such as its liquefaction, low critical temperature, volumetric weight and reversibility [4-7]. Hydrogen-based energy and also hydrogen storage technology have attracted the attention of many scientists and practitioners, leading to public perception and acceptance [2-7]. Although a perfect system has not yet been constructed, it is widely considered that the world economy would really be based on hydrogen energy systems in the forthcoming decades [6]. It is noted here that the US Department of Energy (DOE) [7] provides some criteria for hydrogen-storage applications of commercial viability; two of them are the minimum hydrogen-storage capacity should be $6.5 \mathrm{wt} \%$ and the decomposition temperature between 60 and $120^{\circ} \mathrm{C}$. Most metal hydrides and complex hydrides exceed these limitations under ambient conditions with high gravimetric capacities and volumetric hydrogen density but traditional methods of hydrogen adsorption in appropriate materials do not satisfy industrial requirements [8-12]. Among them, light-weight boron compounds, such as metal tetrahydroborates, could be potential candidates for the high hydrogen storage technology $[9,10,13-15]$.

For example, lithium tetrahydroborate $\mathrm{Li}\left(\mathrm{BH}_{4}\right)$ could be an efficient energy storage compound [16]. Its remarkable properties of high capacity hydrogen storage $(18.5 \mathrm{wt} \%)$ and reversible hydrogen desorption would make it even more promising for mobile technologic applications; however, in practice the main problem is stability [16-19] and also high decomposition temperature [20-22]. Moreover, it is an expensive compound [13]. Thus, the hydrogen economy of $\mathrm{LiBH}_{4}$ and other monovalent tetraborohydrides is not a candidate for today's sustainable energy systems [17,23]. Therefore, the researches, based on material properties, have shown a considerable attention on different light-weight hydrogen storage structures, and there are still some challenges for mixing materials, including alkali metal and other metal tetrahydroborates [23-42]. More recently, novel boron-based compounds have been discovered; examples of some experimental and theoretical studies on bimetallic borohydrides are $\mathrm{KLi}\left(\mathrm{BH}_{4}\right)_{2}$ [25], $\mathrm{KSc}\left(\mathrm{BH}_{4}\right)_{4}[33], \mathrm{Li}\left[\mathrm{Zn}_{2}\left(\mathrm{BH}_{4}\right)_{5}\right]$ and $\mathrm{M}\left[\mathrm{Zn}\left(\mathrm{BH}_{4}\right)_{3}\right]$ salts $(\mathrm{M}=$ $\mathrm{Na}, \mathrm{K})$ [32], $\mathrm{KAl}\left(\mathrm{BH}_{4}\right)_{4}$ [31] by the mixing of $\mathrm{M} 1\left(\mathrm{BH}_{4}\right)_{n}$ with the alkaline metal borohydride $\mathrm{M} 2\left(\mathrm{BH}_{4}\right)_{n}$ and three metallic $\mathrm{Li}_{3} \mathrm{MZn}_{5}\left(\mathrm{BH}_{4}\right)_{15}, \mathrm{M}=\mathrm{Mg}$, Mn [39]. 
In contrast with the alkali and earth alkaline metal tetrahydroborates, aluminium tetrahydroborate $\mathrm{Al}\left(\mathrm{BH}_{4}\right)_{3}$ is in gas phase at $0^{\circ} \mathrm{C}$, unstable at ambient conditions and also decomposes below room temperature $[10,19]$. To overcome these obstacles, more recently Lindemann et al [34] synthesized the Al-Li-borohydride $\mathrm{Al}_{3} \mathrm{Li}_{4}\left(\mathrm{BH}_{4}\right)_{13}$ by a combination of mixing techniques of more stable monovalent tetraborohydride $\mathrm{LiBH}_{4}$ and less stable trivalent tetraborohydride $\mathrm{Al}\left(\mathrm{BH}_{4}\right)_{3}$. They reported [34] structural, physical and chemical characterization of the complex; moreover, $\mathrm{XRD}$ analysis showed that the structure of $\mathrm{Al}_{3} \mathrm{Li}_{4}\left(\mathrm{BH}_{4}\right)_{13}$ is interestingly reorganized on the basis of the complex cation $\left[\left(\mathrm{BH}_{4}\right) \mathrm{Li}_{4}\right]^{3+}$ and the complex anions $\left[\mathrm{Al}\left(\mathrm{BH}_{4}\right)_{4}\right]^{-}$in cubic structure of symmetry group P-43N(IT:218) with $a=11.3640 \AA$. On this aspect $[23,34]$, there are calculations of structure of $\mathrm{Al}_{3} \mathrm{Li}_{4}\left(\mathrm{BH}_{4}\right)_{13}$ by various methods based on the first principles and stable phases of the Al-Li-borohydrides [43]. Three phases of not previously reported $\mathrm{AlLi}\left(\mathrm{BH}_{4}\right)_{4}$ compounds [23] within tetragonal and orthorhombic symmetry have been reported as potential hydrogen storage compounds [43]. In another recent study of Lindeman et al [44], the decomposition pathway of $\mathrm{Al}_{3} \mathrm{Li}_{4}\left(\mathrm{BH}_{4}\right)_{13}$ was described experimentally at ambient pressure via the decomposition product of the monometallic borohydrides $\mathrm{Li}\left(\mathrm{BH}_{4}\right)$ and $\mathrm{Al}\left(\mathrm{BH}_{4}\right)_{3}$. To the best of our knowledge, other possible decomposition reactions, pressuredependent properties and the photon excitation properties of $\mathrm{Al}_{3} \mathrm{Li}_{4}\left(\mathrm{BH}_{4}\right)_{13}$ have not been reported yet. The electro-optical properties and the effect of pressure on hydrogen storage materials are worth investigating by density functional theory (DFT).

In this study, we revisit $\mathrm{Al}-\mathrm{Li}$-tetrahydroborate $\mathrm{Al}_{3} \mathrm{Li}_{4}$ $\left(\mathrm{BH}_{4}\right)_{13}$ and other sub-units of the compound to calculate the possible decomposition reactions, electronic and the photon excitation properties and also pressure-dependent properties. Moreover, a detailed theoretical study of pressuredependent electronic and mechanical properties, Mulliken atomic charges and bond populations with calculated bond lengths is conducted at the pressure of $0-50 \mathrm{GPa}$. In the following, the evolution of our pressure-dependent results is analysed, and then discussed in connection with changes in the mechanical and electronic properties.

\section{Method}

Calculations were carried out by an ab-initio plane-wave pseudo-potential DFT approximation as implemented in Castep package [45]. The ion-electron interaction was modelled using the Vanderbilt ultrasoft pseudopotential [46] and exchange-correlation effects were treated within the generalized gradient approximation (GGA) by the recently revised Perdew-Burke-Ernzerhof (RPBE) approach [47] for solids, which is known to yield more accurate results, such as bond lengths and cell parameters, compared with the traditional local density approximations. After convergence tests, the cut-off energy of $600 \mathrm{eV}$ was found to be sufficient for total energies; a Monkhorst-Pack special $k$-point set of unit cell was used with $0.02 \AA^{-1}$ and $k$-point spacing scheme of $(4 \times 4 \times 4)$ with $124 k$-points. Throughout the calculations, all atomic coordinates and unit cell parameters were fully relaxed using the BFGS algorithm [48] (proposed by Broyden, Fletcher, Goldfarb and Shannon). The optimizations satisfied the following convergence criteria: (i) total energy of $5.0 \times 10^{-6} \mathrm{eV}$ per atom, (ii) the maximum force acting on each atom of $0.01 \mathrm{eV} \AA^{-1}$, (iii) the maximum displacement of $5.0 \times 10^{-4} \AA$ and (iv) the maximum stress acting on each atom was less than $0.02 \mathrm{GPa}$. It is noted here that the ultrafine cut-off energy of the Castep program is $330 \mathrm{eV}$ and $k$-point set of unit cell is $2 \times 2 \times 2$; hence our choice for the calculation configuration highly improved the quality of DFT calculations. To validate our calculations we also reoptimized the unit cell with a different simulation approach: the local density approach (LDA) of Castep package [45]; LDA optimization was performed with the same convergence criteria of RPBE calculations (mentioned earlier). To test the stability, quantum molecular dynamics (MD) simulation of two unit cells of $\mathrm{Al}_{3} \mathrm{Li}_{4}\left(\mathrm{BH}_{4}\right)_{13}$ was performed at room temperature $(298 \mathrm{~K})$ and $0 \mathrm{GPa}$ pressure with an NPT ensemble. The MD simulations were carried out with a Nose-Hoover chain thermostat and Andersen-Hoover barostat [45] for 1.0 ps with a 1.0 fs time step.

Then, the photon excitation properties of cubic structure of $\mathrm{Al}_{3} \mathrm{Li}_{4}\left(\mathrm{BH}_{4}\right)_{13}$ were calculated, related to the frequencydependent complex dielectric function $\varepsilon(w)=\varepsilon_{1}(w)+$ $i \varepsilon_{2}(w)$. The imaginary part, $\varepsilon_{2}(w)$, was found from the optical transitions between the occupied and unoccupied states, and the real part, $\varepsilon_{1}(w)$, was derived from the imaginary part using the Kramer-Kronig relation [49]. Other photon excitation properties such as energy loss function can be derived from the real and imaginary parts of the complex dielectric function [50]. In the last step, the hydrostatic-pressure-dependent properties of $\mathrm{Al}_{3} \mathrm{Li}_{4}\left(\mathrm{BH}_{4}\right)_{13}$ were calculated in the range of 0-50 GPa hydrostatic pressure.

\section{Results and discussion}

\subsection{Structural properties}

$\mathrm{Al}_{3} \mathrm{Li}_{4}\left(\mathrm{BH}_{4}\right)_{13}$ is in cubic symmetry and consists of binuclear complex anions $\left[\mathrm{Al}\left(\mathrm{BH}_{4}\right)_{4}\right]^{1-}$ and cations $\left[\mathrm{Li}_{4}\left(\mathrm{BH}_{4}\right)\right]^{3+}$. The crystal structure contains one cation and three anions in the formula unit (see figure 1). It is interesting that both cation and anion involve tetraborohydride $\left\{\mathrm{BH}_{4}\right\}^{-}$ions, where the complex cation $\left[\mathrm{Li}_{4}\left(\mathrm{BH}_{4}\right)\right]^{3+}$ is constructed as an $\left\{\mathrm{BH}_{4}\right\}^{-}$ anion surrounded by tetrahedral $\mathrm{Li}^{+}$cations, and an $\mathrm{Al}^{3+}$ cation is surrounded by four $\left\{\mathrm{BH}_{4}\right\}^{-}$anions in the complex anion $\left[\mathrm{Al}\left(\mathrm{BH}_{4}\right)_{4}\right]^{-}$. Covalently bonded complex $\left\{\mathrm{BH}_{4}\right\}^{-}$ anions play a key role in the formation of the complex structure as indicated previously [51] for the structures of metal cation and the tetrahydroborate anions. As shown in figure $1 \mathrm{a}$, the complex cation $\left[\mathrm{Li}_{4}\left(\mathrm{BH}_{4}\right)\right]^{3+}$ is alienated by four 
(a)

(b)
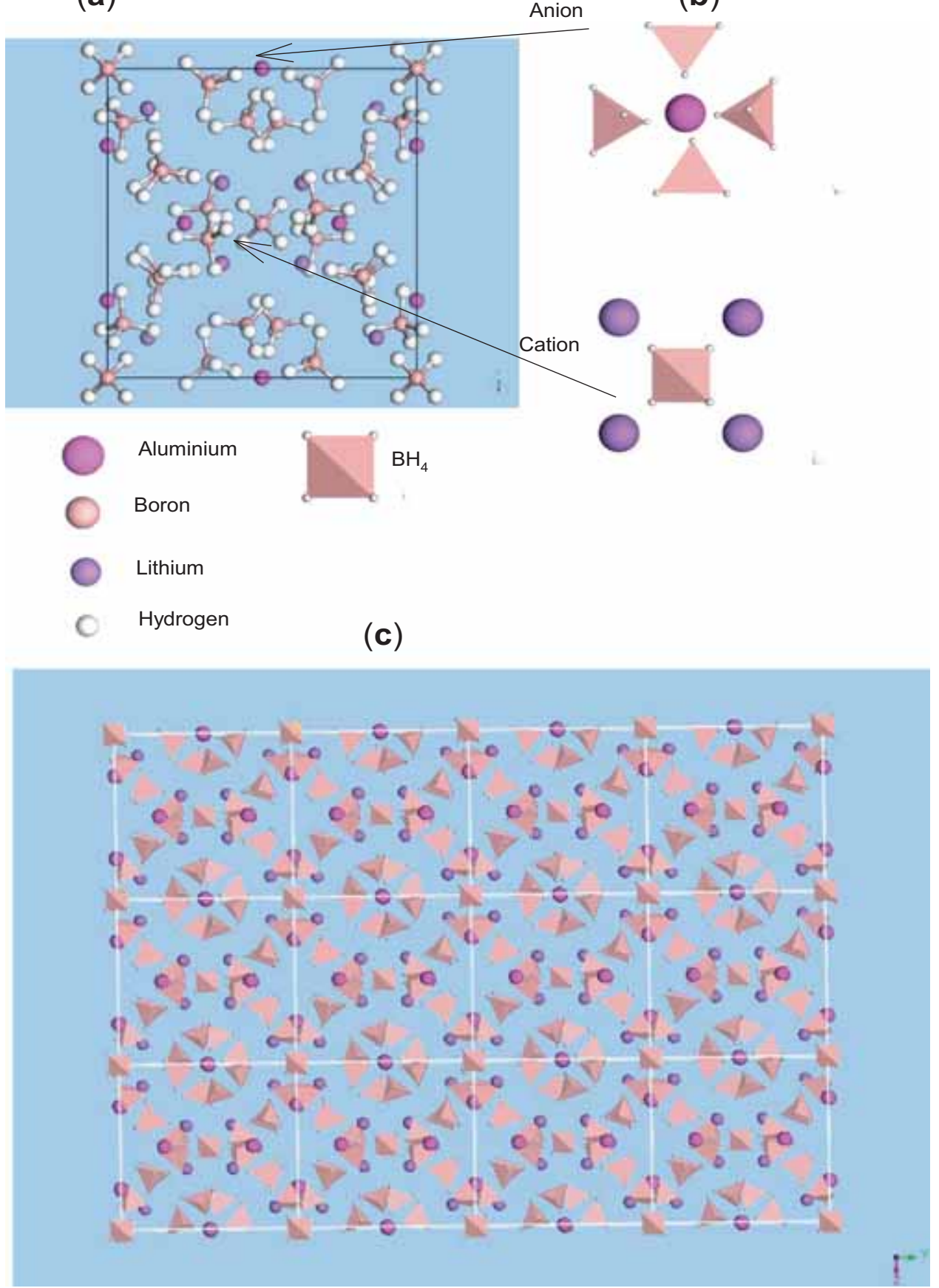

Figure 1. (a) Unit cell of $\mathrm{Al}_{3} \mathrm{Li}_{4}\left(\mathrm{BH}_{4}\right)_{13}$ consists of binuclear complex anions $\left[\mathrm{Al}\left(\mathrm{BH}_{4}\right)_{4}\right]^{-}$and cations $\left[\mathrm{Li}_{4}\left(\mathrm{BH}_{4}\right)\right]^{3+}$. (b) Anion $\left[\mathrm{Al}\left(\mathrm{BH}_{4}\right)_{4}\right]^{-}$, in which aluminium is surrounded by distorted tetrahedrons of $\mathrm{BH}_{4}$, and the cation, $\left[\mathrm{Li}_{4}\left(\mathrm{BH}_{4}\right)\right]^{3+}$, in which $\mathrm{BH}_{4}$ anion is tetrahedrally surrounded by lithium atoms. (c) The super-cell of $\mathrm{Al}_{3} \mathrm{Li}_{4}\left(\mathrm{BH}_{4}\right)_{13}$.

$\left[\mathrm{Al}\left(\mathrm{BH}_{4}\right)_{4}\right]^{-}$anions, which confirms the trend of the average high-symmetry central position. In the undistorted tetrahedral cation structure, lithium and boron atoms are located at $8 \mathrm{e}$ and 2a Wychkoff positions, respectively, which have equivalent $\mathrm{Li}-\mathrm{B}$ distances and also almost equivalent $\mathrm{B}-\mathrm{H}$ bond lengths for its sub-ion of $\left\{\mathrm{BH}_{4}\right\}^{1-}$. In the anion structure, distorted tetrahedral units are formed by $\left\{\mathrm{BH}_{4}\right\}^{1-}$ anions, in which aluminium and boron atoms are located at $6 \mathrm{c}$ and $24 \mathrm{i}$ Wychkoff positions, respectively. It is important that all $\mathrm{Al}-\mathrm{B}$ bond lengths are nearly equivalent but $\mathrm{B}-\mathrm{H}$ bond lengths for sub-ion of $\left\{\mathrm{BH}_{4}\right\}^{1-}$ are different, where the $\mathrm{B}-\mathrm{H}$ bond lengths of the nearest neighbour hydrogen of aluminium are longer 
Table 1. Some physical properties of cubic $\mathrm{Al}_{3} \mathrm{Li}_{4}\left(\mathrm{BH}_{4}\right)_{13}$, which were fully optimized by DFT approach in the levels of GGA-RPBE and LDACA-PZ.

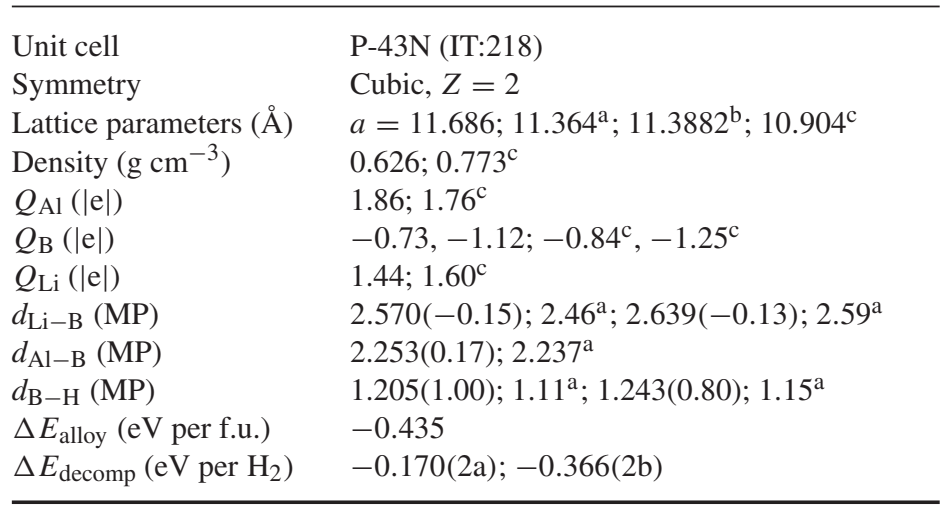

International crystallographic numbers are given within brackets, and also the corresponding lattice parameters, charge of individual atoms, bond lengths $(\AA)$ of nearest neighbour atoms and the Mulliken populations (MPs) of bonds in optimized unit cells. The pseudo-band gap $E_{\mathrm{Gap}}$ (in $\mathrm{eV}$ ) refers to the energy difference between the top of the valence band and the bottom of the conduction band. In the last two lines, alloying and decomposition reactions of the $\mathrm{Al}-\mathrm{Li}$-tetrahydroborates are given. The decomposition energies for (2a) and (2b) reaction pathways are defined in the text. ${ }^{\text {a}}$ Experimental data at $-173^{\circ} \mathrm{C}$.

${ }^{\mathrm{b}}$ Theoretical results (GGA of DFT) from Ref. [34].

${ }^{\mathrm{c}} \mathrm{LDA}$ results.

than that of others. Our fully relaxed geometry optimization results of the unit cell in cubic structure with P-43N symmetry are given in table 1 . The calculated unit cell parameters and bond lengths from both approximations look very similar and agree well with each other; the values of the lattice parameter $a$ with the LDA level of DFT are about $6.7 \%$ smaller than that of RPBE result. The calculated lattice parameter $a$ is also in reasonable agreement with previously reported values, with an overestimation by about 2.76 and $2.55 \%$ from experimental and theoretical results [34], respectively. It is notable that $\mathrm{Al}_{3} \mathrm{Li}_{4}\left(\mathrm{BH}_{4}\right)_{13}$ also has a highly porous structure $\left(\rho=0.626 \mathrm{~g} \mathrm{~cm}^{-3}\right)$. As seen from table 1 , the unit cell is optimized and then structural and electronic properties are obtained in our calculations with the revised GGA, which are in good accordance with the previous experimental and theoretical results [34].

\subsection{Alloy and decomposition reaction pathways}

Next, the stability and possible reaction pathways of the structure was studied. In our MD simulation of $2\left[\mathrm{Al}_{3} \mathrm{Li}_{4}\left(\mathrm{BH}_{4}\right)_{13}\right]$, a conformational transition was observed from the face centred cubic symmetry to P1 symmetry after 0.083 ps of the simulation at the ambient conditions. Although $1.0 \mathrm{ps}$ time MD simulation is computationally quite costly, it is not long enough to decide on statistically meaningful features but it does suggest that at the ambient temperature the system does not have long time in cubic symmetry, which has already been pointed out experimentally [34].
The stability may be analysed against its phase separation into the original binary borohydrides, according to the reactions that have been defined previously [34]; the decomposition pathway into two product tetra borohydrides is

$$
\mathrm{Al}_{3} \mathrm{Li}_{4}\left(\mathrm{BH}_{4}\right)_{13} \rightarrow 4\left(\mathrm{LiBH}_{4}\right)+3 \mathrm{Al}\left(\mathrm{BH}_{4}\right)_{3} .
$$

In this decomposition reaction, the stability range of $\Delta E_{\text {alloy }}$ $\leq 0.0 \mathrm{eV}$ per f.u. is used, which was proposed as a criterion for alloys [23]. For these reactions, the alloy energies can be defined as

$$
\begin{aligned}
\Delta E_{\text {alloy }}= & E\left[\mathrm{Al}_{3} \mathrm{Li}_{4}\left(\mathrm{BH}_{4}\right)_{13}\right]-\left(4 E\left[\mathrm{Li}\left(\mathrm{BH}_{4}\right]\right)\right. \\
& \left.+3 E\left[\mathrm{Al}\left(\mathrm{BH}_{4}\right)_{3}\right]\right)
\end{aligned}
$$

where $E[\ldots]$ is the total energy of corresponding structure. According to this reaction, the compound decomposes only to its components, solid $\mathrm{LiBH}_{4}$ and gas phase $\mathrm{Al}\left(\mathrm{BH}_{4}\right)_{3}$, which desorb 18.5 and $16.8 \mathrm{wt} \%$ amounts of hydrogen and decompose above $350^{\circ} \mathrm{C}$ and near room temperature [23,34], respectively. However, the low-temperature desorption of $\mathrm{LiBH}_{4}$ releases only a small amount $(0.3 \mathrm{wt} \%)$ of hydrogen [8]. It should be pointed out that the decomposition energies for both kind of tetraborahydrides, $\mathrm{LiBH}_{4}$ and $\mathrm{Al}\left(\mathrm{BH}_{4}\right)_{3}$, are well known [16-19,52], and the decomposition pathways of $\mathrm{Al}\left(\mathrm{BH}_{4}\right)_{3}$ were previously described $[44,52,55]$. In addition to the phase separations, hydrogen would be released in the decomposition reaction pathways; this may be possible for $\mathrm{Li}-\mathrm{Al}$ double cation tetraborahydrides at low temperatures. 
As the $\mathrm{LiBH}_{4}$ component is very stable a considerable $\mathrm{H}$-release proceeds at over 375-650 K $[19,53]$; on the contrary, the other component $\mathrm{Al}\left(\mathrm{BH}_{4}\right)_{3}$ is very unstable at room temperature; it is in gas phase at $0^{\circ} \mathrm{C}$, its boiling point is $45^{\circ} \mathrm{C}$ $[52,54]$ and it has a very low decomposition temperature of about $70^{\circ} \mathrm{C}[55,56]$. Thus, it easily releases hydrogen at room temperature and upon heating [57]. Therefore, the stability criteria of alloys [23] could be less favourable for decomposition of $\mathrm{Al}_{3} \mathrm{Li}_{4}\left(\mathrm{BH}_{4}\right)_{13}$ as a double-cation tetraborahydride. It is noted here that most complex hydrides encounter simple kinetic problems also in desorbing hydrogen [5]. Finally, $\mathrm{Al}_{3} \mathrm{Li}_{4}\left(\mathrm{BH}_{4}\right)_{13}$, being lightweight, having low manufacture cost and a high theoretical hydrogen storage capacity (17.37 wt $\%$ of $\mathrm{H}_{2}$ ), is an attractive hydrogen storage material; however, it may release most of the contained hydrogen by appropriate decomposition reactions as follows.

On carefully examining similar reactions [17,23,31], the first of two decomposition reaction pathways could be possible for $\mathrm{Al}_{3} \mathrm{Li}_{4}\left(\mathrm{BH}_{4}\right)_{13}$ as follows:

$$
\begin{aligned}
\mathrm{Al}_{3} \mathrm{Li}_{4}\left(\mathrm{BH}_{4}\right)_{13} \rightarrow & 4\left(\mathrm{LiBH}_{4}\right)+9 / 2\left(\mathrm{~B}_{2} \mathrm{H}_{6}\right) \\
& +9 / 2\left(\mathrm{H}_{2}\right)+3 \mathrm{Al},
\end{aligned}
$$

which is a more feasible reaction for the other tetraborahydrides [23]. This pathway is different from that of recently synthesized double metallic borohydrides, $\mathrm{M}\left[\mathrm{Al}\left(\mathrm{BH}_{4}\right)_{4}\right][31$, 54], which release diborane with desorption of free hydrogen. However, hydrogen desorption from borohydrides is often accompanied by the release of diborane; it was previously reported for many desorptions of tetrahydroborates $[23,25,32,33,39]$. The second generic decomposition reaction pathway can be shown as follows:

$$
\mathrm{Al}_{3} \mathrm{Li}_{4}\left(\mathrm{BH}_{4}\right)_{13} \rightarrow 4 \mathrm{LiH}+3 \mathrm{Al}+13 \mathrm{~B}+24\left(\mathrm{H}_{2}\right) .
$$

The existence of an intermediate phase of $\mathrm{LiH}$ and its structure is well known [23], which has high stability and also high desorption temperature (above $1000 \mathrm{~K}$ ) [17]; therefore, it is not usually decomposable in the decomposition reaction of $\mathrm{Al}_{3} \mathrm{Li}_{4}\left(\mathrm{BH}_{4}\right)_{13}$.

Corresponding decomposition energies for both reaction pathways can be formulated as follows:

$$
\begin{aligned}
\Delta E_{\text {decomp }}= & E\left[\mathrm{Al}_{3} \mathrm{Li}_{4}\left(\mathrm{BH}_{4}\right)_{13}\right]-\left\{4 E\left[\mathrm{LiBH}_{4}\right]\right. \\
& \left.+3 E[\mathrm{Al}]+9 / 2 E\left[\mathrm{~B}_{2} \mathrm{H}_{6}\right]+9 / 2 E\left[\mathrm{H}_{2}\right]\right\}
\end{aligned}
$$

and

$$
\begin{aligned}
\Delta E_{\text {decomp }}= & E\left[\mathrm{Al}_{3} \mathrm{Li}_{4}\left(\mathrm{BH}_{4}\right)_{13}\right]-\{4 E[\mathrm{LiH}]+3 \mathrm{E}[\mathrm{Al}] \\
& \left.+13 E[\mathrm{~B}]+24 E\left[\mathrm{H}_{2}\right]\right\}
\end{aligned}
$$

where $E[\ldots]$ is the total energy of corresponding structure and free aluminium and boron atoms and gas hydrogen and borane molecules. In the first decomposition reaction (equation (2a)), the compound $\mathrm{Al}_{3} \mathrm{Li}_{4}\left(\mathrm{BH}_{4}\right)_{13}$ releases 18 hydrogen molecules $\left(27 / 2\right.$ of them from diborane $\left.9 / 2\left(\mathrm{~B}_{2} \mathrm{H}_{6}\right)\right)$, totally about $12.03 \mathrm{wt} \%$. It should be realized that diborane is in gas phase in the ambient conditions with the melting point of $-165.5^{\circ} \mathrm{C}$ and the boiling point of $-92.5^{\circ} \mathrm{C}$ [58], which is an permanent barrier to reversibility [59].

The second decomposition reaction energy $\Delta E_{\text {decomp }}$ (equation (2b)) indicates the stability of the alloy, which is against the decomposition reaction [23], and in this reaction the compound $\mathrm{Al}_{3} \mathrm{Li}_{4}\left(\mathrm{BH}_{4}\right)_{13}$ releases more hydrogen, 24 hydrogen molecules or about $16.04 \mathrm{wt} \%$.

As seen from table 1, both decomposition reaction energies $\left(-0.170 \mathrm{eV}\right.$ per $\mathrm{H}_{2}$ molecule for $(2 \mathrm{a})$ and $-0.366 \mathrm{eV}$ per $\mathrm{H}_{2}$ molecule for $(2 \mathrm{~b})$ ) of $\mathrm{Al}_{3} \mathrm{Li}_{4}\left(\mathrm{BH}_{4}\right)_{13}$ are negative. Züttel et al [17] discussed the stability of tetrahydroborates from different viewpoints; also, in a recent study, the stability criteria were obtained by Hummelshøj et al [23] as the energy stability range of $E_{\text {alloy }}<0.0 \mathrm{eV}$ per f.u. and $E_{\text {decomp }}\{-0.5 ; 0.0\} \mathrm{eV}$ per $\mathrm{H}^{2}$ molecule. According to our knowledge, although both reactions satisfy the stability criterria [23], and decomposition analyses of $\mathrm{Al}_{3} \mathrm{Li}_{4}\left(\mathrm{BH}_{4}\right)_{13}$ have been already reported experimentally with the thermogravimetric (TG) analysis in combination with infrared spectroscopy (FT-IR) [44], and also by Raman, synchrotron powder X-ray diffraction and differential scanning calorimetry (DSC) [34], unfortunately, the experimental results on the reversibility properties of decomposition pathways have not appeared yet.

\subsection{Electro-optical properties}

In addition to structural and MD optimizations, the electronic density of states (DOS) of $\mathrm{Al}_{3} \mathrm{Li}_{4}\left(\mathrm{BH}_{4}\right)_{13}$ was calculated; the profile is depicted in figure 2. The Fermi level is set at zero in the DOS profile. As seen from figure 2, except the sharp peak located at very low energy (at about $-43.7 \mathrm{eV}$ from $2 \mathrm{~s}$ orbital of $\mathrm{Li}$ ), there are four discrete group of PDOS in the range -10 to $10 \mathrm{eV}$. Note that DOS is not exactly zero at the Fermi level (we have repeated the calculations with different gradient-corrected exchange-correlation functionals, including the smearing effects arising due to the large width of the DOS peaks. The DOS profile at the Fermi level never goes to zero for different smearing values (from 0.2 to 0.005 )) but there is an energy gap of about $\sim 7.0 \mathrm{eV}$ between the lowest conduction band state and top of the valence band state, which is defined as the quasiparticle band gap (or DFT Kohn-Sham band gap, $\left.E_{\mathrm{Gap}}=E_{\mathrm{c}}-E_{\mathrm{v}}\right) . E_{\mathrm{v}}$ and $E_{\mathrm{c}}$ represent the valence band maximum (VBM) or the highest occupied molecular orbital (HOMO) and the conduction band minimum (CBM) or the lowest unoccupied molecular orbital (LUMO), respectively. At the vicinity of the Fermi level, DOS essentially originates from $s-p$ hybrid orbitals of Al-containing complex anion $\left[\mathrm{Al}\left(\mathrm{BH}_{4}\right)_{4}\right]^{-}$and Li-containing complex cations $\left[\mathrm{Li}_{4}\left(\mathrm{BH}_{4}\right)\right]^{3+}$. However, the peak located at about $-2.8 \mathrm{eV}$ is dominated by anion $\mathrm{s}-\mathrm{p}$ hybrid orbitals and the peak at about 


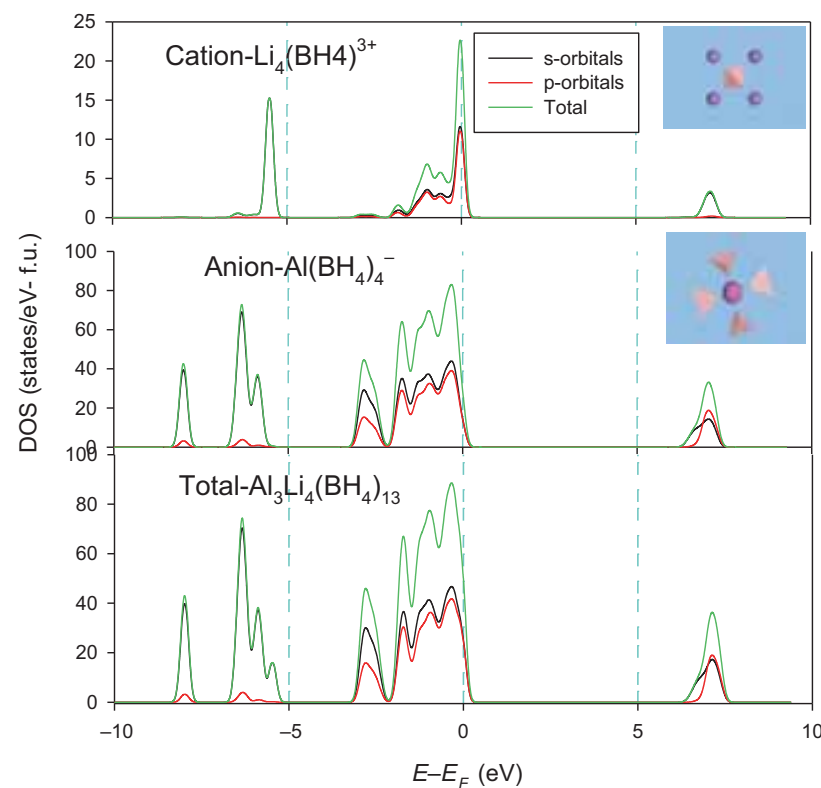

Figure 2. Calculated partial density of states for $\mathrm{Al}_{3} \mathrm{Li}_{4}\left(\mathrm{BH}_{4}\right)_{13}$. Fermi level (dashed vertical line) is shifted to $0.0 \mathrm{eV}$. Smearing parameter is chosen as 0.05 .

$-5.5 \mathrm{eV}$ comes from s-electrons of cation; the peaks located at about $-5.9,-6.3$ and $-8.0 \mathrm{eV}$ come from s-electrons of the anion. In the structure of complex anion, $\left[\mathrm{Al}\left(\mathrm{BH}_{4}\right)_{4}\right]^{-}$, each $\mathrm{Al}^{3+}$ cation is surrounded tetrahedrally by four distorted $\mathrm{BH}_{4}^{-}$ anions with $\mathrm{a} 4+4$ coordination of $\mathrm{H}$ to $\mathrm{Al}$, which is formed as an anion $\left[\mathrm{Al}\left(\mathrm{BH}_{4}\right)_{4}\right]^{-}$, i.e., the anion involves a cation. The anions play a key role in the structure as indicated. On the other hand, chemical bonding nature in $\mathrm{Al}_{3} \mathrm{Li}_{4}\left(\mathrm{BH}_{4}\right)_{13}$ can be clarified by means of Mulliken atomic charge and bond populations. First of all, Mulliken atomic charges and bond overlap populations (MPs) are strongly dependent on the data set of unit cell. It is noted that positive and negative values of the population indicate bonding and anti-bonding states, respectively, and high positive value of MP indicates a high degree of covalency in the bond [60]. Because of the structural symmetry of the complex anion, $\left[\mathrm{Al}\left(\mathrm{BH}_{4}\right)_{4}\right]^{-}$, the distances of nearest neighbours of aluminium-boron are almost equivalent. However, both types of boron atoms have negative charges; one of them, of $\mathrm{Al}_{3} \mathrm{Li}_{4}\left(\mathrm{BH}_{4}\right)_{13}$, has -1.12 electron, which is in the cation, and the others (12) have -0.73 electron (as acceptor) in the anion structure, and all three aluminium atoms donate 1.86 electrons, i.e., hole charge (see table 1). The both types of boron atoms refer to the boron atoms, which have only different locations. Finally, our DFT approximation results revealed that $\mathrm{Al}_{3} \mathrm{Li}_{4}\left(\mathrm{BH}_{4}\right)_{13}$ has distorted tetrahedral complex anions $\left[\mathrm{Al}\left(\mathrm{BH}_{4}\right)_{4}\right]^{-}$and cation $\left[\mathrm{Li}_{4}\left(\mathrm{BH}_{4}\right)\right]^{3+}$.

From the response of $\mathrm{Al}_{3} \mathrm{Li}_{4}\left(\mathrm{BH}_{4}\right)_{13}$ to photon excitation, the dielectric function and energy loss function were calculated, which are shown in figure $3 \mathrm{a}$ and $\mathrm{b}$, respectively. We note here that to calculate the photon excitation properties of a material it is efficient to calculate the complex dielectric
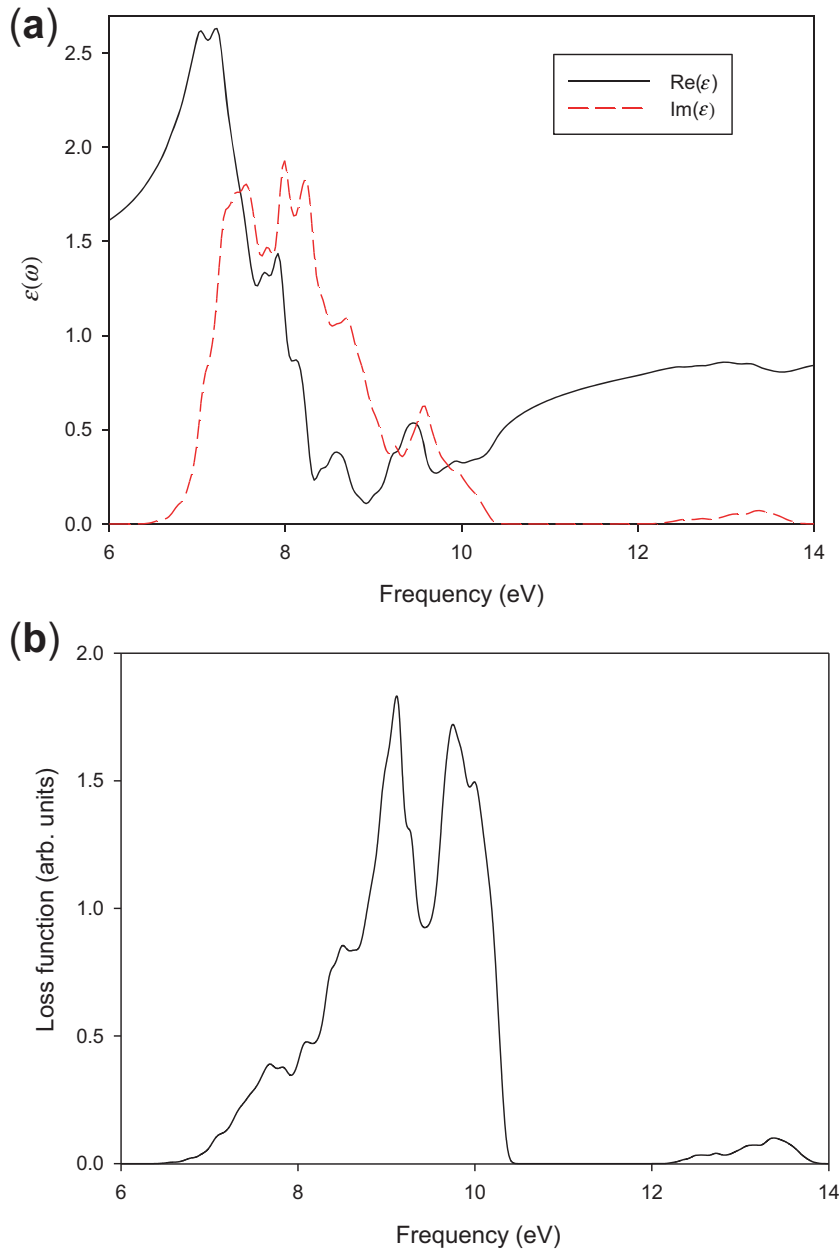

Figure 3. Calculated photon excitation properties of $\mathrm{Al}_{3} \mathrm{Li}_{4}\left(\mathrm{BH}_{4}\right)_{13}$ compound. (a) Real and imaginary parts of the dielectric function and (b) the electron energy loss function. The spectra are calculated with the smearing parameter of $0.05 \mathrm{eV}$. Unpolarized incident direction of $\gamma$-ray is [100].

function, $\varepsilon=\varepsilon_{1}+i \varepsilon_{2}$. However, there is a relation between electronic DOS and optical parameters of the crystal structures. It is known that the imaginary part of the dielectric function $\varepsilon_{2}$ is related to the electronic transition between interenergy bands [49]; for dipole transitions from an initial state $E_{i}$ to the final state $E_{f}$, the relation is defined by the relation [61]

$$
\varepsilon_{2}(\omega)=\left(A / \omega^{2}\right) \sum_{i f} \int\left|M_{i f}\right| \delta\left(E_{f}(k)-E_{i}(k)-\hbar \omega\right) \mathrm{d} k,
$$

where $A=\hbar \pi^{2} e^{2} / m^{2}$ is a constant, the integral is over the unit cell, summation over all initial valence band and conduction band states of allowed ones and $M_{i f}$ is the momentum matrix element for interband transitions. The real and imaginary pars of the dielectric function are related to each other by the Kramers-Kronig relations; for details see the references $[49,61]$. Calculated real and imaginary parts of complex 
dielectric function are plotted in figure $3 \mathrm{a}$, which have several shoulders, maxima and minima in the energy range of 6-14 $\mathrm{eV}$. As seen from figure $3 \mathrm{a}$, the region of the major peaks of the imaginary part is $7-10 \mathrm{eV}$ (far ultraviolet region). The main peaks, located at $7.43 \mathrm{eV}(\sim 167 \mathrm{~nm}), 7.54,7.98,8.70$ and $8.84 \mathrm{eV}(\sim 140 \mathrm{~nm})$, are dominated by interband transition of $\mathrm{s}-\mathrm{p}$ hybrid orbital of the complex anion, $\left[\mathrm{Al}\left(\mathrm{BH}_{4}\right)_{4}\right]^{1-}$.

On the other hand, the energy loss spectrum describes the grouping travel of the electrons into the conduction bands [50] and is given by inverse of imaginary part of the complex dielectric function:

$$
L(w)=\frac{\varepsilon_{2}(w)}{\varepsilon_{1}^{2}(w)+\varepsilon_{2}^{2}(w)},
$$

which gives the energy loss of a fast electron traversing the material [62].

Calculated energy loss function of $\mathrm{Al}_{3} \mathrm{Li}_{4}\left(\mathrm{BH}_{4}\right)_{13}$ gives two well-groomed peaks with shoulders, the first located at $\sim 9.10 \mathrm{eV}\left(\sim 136 \mathrm{~nm}\right.$, far ultraviolet region) from $\left[\mathrm{Li}_{4}\left(\mathrm{BH}_{4}\right)\right]^{3+}$ cation and the second peak at $\sim 9.73 \mathrm{eV}(\sim 127 \mathrm{~nm}$, far ultraviolet region) from $\left[\mathrm{Al}\left(\mathrm{BH}_{4}\right)_{4}\right]^{-}$anion (see figure $3 \mathrm{~b}$ ). Unfortunately, there are no experimental and calculated photon excitation data yet (to the knowledge of the author) for comparison, but two main maxima in our good-quality energy loss function spectra indicate that the anion-cation structure is found to be in very good agreement with the experiment [34].

\subsection{Pressure-dependent behaviour}

The pressure dependence of material properties is a very useful concept; from the pressure-dependent behaviours of $\mathrm{Al}_{3} \mathrm{Li}_{4}\left(\mathrm{BH}_{4}\right)_{13}$, electronic and thermodynamic parameters

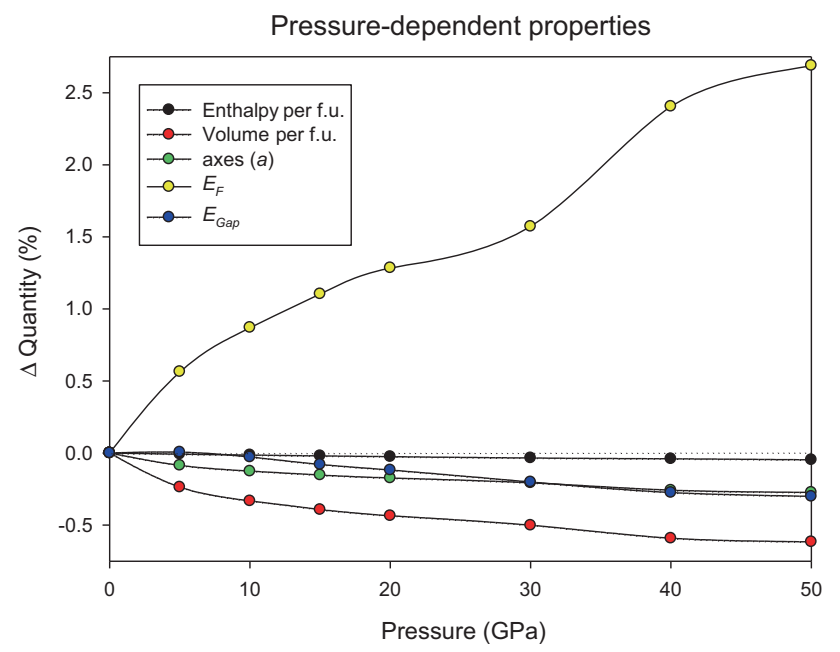

Figure 4. Pressure effect on $\mathrm{Al}_{3} \mathrm{Li}_{4}\left(\mathrm{BH}_{4}\right)_{13}$ : the behaviours of structural parameters (normalized). The enthalpy per formula unit, Fermi level and the quasiparticle energy gap $\left(E_{\mathrm{Gap}}\right)$ between VBM and CBM, under hydrostatic pressure of 0-50 GPa. were calculated by applying hydrostatic pressure in the range of 0-50 GPa. As seen from figure 4, the enthalpy, the pseudoband gap (quasiparticle band gap, $E_{\mathrm{Gap}}$ ), also lattice parameter $(a)$, and the volume $(V)$ decrease monotonically, whereas in normal semiconductors the band gap increases. It can be seen from calculated data that when the pressure increases the location of Fermi energy level increases, which is strongly dependent on the pressure, i.e., the Fermi energy level moves up to the conduction band (from about 2.0 to about $7.3 \mathrm{eV}$ ). As the valence band is the source of electrons and the possible quantum levels lie as the acceptor levels, if the applied pressure on the material increases, the acceptor levels are gradually filled and the Fermi level shifts upwards. However, in the pressure range 0-50 GPa the pseudo-band gap (quasiparticle band gap) $E_{\mathrm{Gap}}=6.41 \mathrm{eV}$ at $0 \mathrm{GPa}$ pressure is decreased smoothly to $4.48 \mathrm{eV}$ at $50 \mathrm{GPa}$ pressure. Since the band gap is well known to be underestimated in the GGA approach, the actual metallization might happen at pressures below $50 \mathrm{GPa}$.

On the other hand, for a small decrease of volume, it is found that the behaviour of the Fermi energy under pressure can be related to $V / V_{0}$ ratio as follows:

$$
E_{F}=E_{F}(0)\left(V / V_{0}\right)^{-\delta},
$$

where $E_{F}(0)$ and $V_{0}$ are the Fermi energy and volume at $0 \mathrm{GPa}$, respectively, and $\delta \approx 1.5$ up to about $40 \%$ volume change, as implemented by Vasvari [63] for face-centred divalent cubic metals.

In the anion-cation structures, pressure dependence of charge transfer should be a good investigator of the structures because of the change in the rate of charge transfer. For example, in the anion $\left[\mathrm{Al}\left(\mathrm{BH}_{4}\right)_{4}\right]^{-}$-cation $\left[\mathrm{Li}_{4}\left(\mathrm{BH}_{4}\right)\right]^{3+}$ structure of $\mathrm{Al}_{3} \mathrm{Li}_{4}\left(\mathrm{BH}_{4}\right)_{13}$ the charge is transferred from $\left(\mathrm{BH}_{4}\right)^{-}$to the electropositive aluminium, and in the cation from $\left(\mathrm{BH}_{4}\right)^{-}$to the electropositive lithium. We can say that these phenomena are a prototype of charge transfer formalism of the ZintlKlemm theory [64]. According to this theory charge transfer and covalent interactions in intermetallic compounds, implying that Zintl phases, are a compound class bridging metallic, ionic and covalent substances [65].

As seen from table 1, at zero pressure, lithium and aluminium atoms almost lose $2 \mathrm{~s}$ and $3 \mathrm{~s}$ electrons, respectively (are becoming donor atoms), thus gaining positive charge. Pressure-dependent charges of individual atoms are depicted in figure 5. As seen from figure 5, the change in charges of $\mathrm{Al}$ and $\mathrm{B}$ atom is very smooth for $0-30 \mathrm{GPa}$ pressure; however, the charge of $\mathrm{Li}$ increases from +1.44 to +1.91 e. For $30-50$ $\mathrm{GPa}$ compression, the charges of boron atoms in cation and anion change very rapidly; it reduces from -0.84(e) (at 30 $\mathrm{GPa}$ ) to -0.51 (e) (at $50 \mathrm{GPa}$ ) for boron in anion, and increases from -1.16(e) (at $30 \mathrm{GPa}$ ) to -1.32(e) (at $50 \mathrm{GPa}$ ) for boron in cation. Moreover, total charges of cations and anions, which are the constituent parts of the structure, are dependent on applied pressure, as well as the structural parameters such 


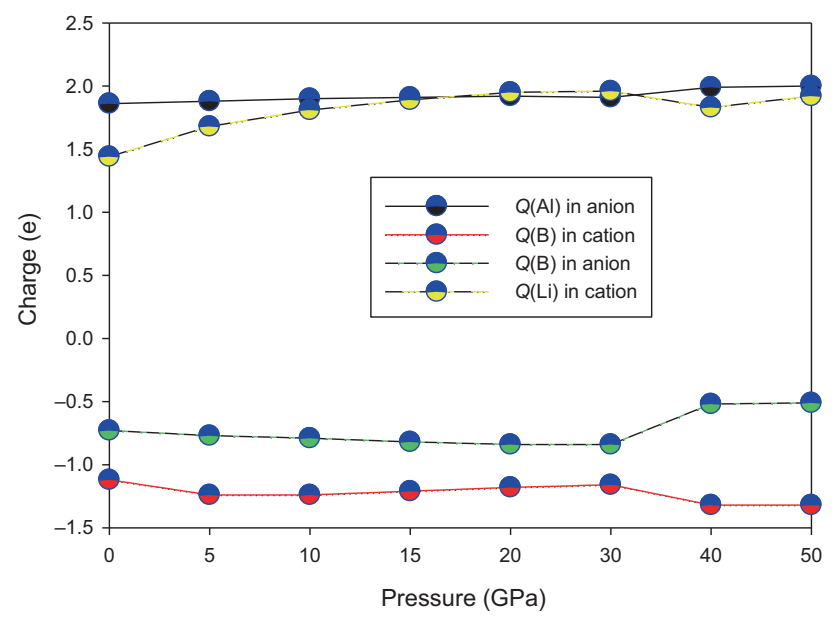

Figure 5. Pressure effect on electronic charge transfer of $\mathrm{Al}_{3} \mathrm{Li}_{4}\left(\mathrm{BH}_{4}\right)_{13}$. Calculated charges of individual atoms of aluminium, boron and lithium in anion and cation under hydrostatic pressure of 0-50 GPa.

as bond lengths and cell axes. Our DFT calculations show that the cation has totally about $+4.4|\mathrm{e}|$ charge at $0 \mathrm{GPa}$ and the same cation has totally $+5.92|\mathrm{e}|$ charge at $50 \mathrm{GPa}$; on the other hand, the Mulliken bond population of $\mathrm{B}-\mathrm{H}$ bonds increases from 0.99 to 1.22 , whereas bond length decreases from 1.223 to $1.180 \AA$. This behaviour continues throughout; the amount of charge transfer increases with increasing pressure; however, boron atoms become negatively charged (as acceptor) at all pressures; therefore, every hydrogen atom appears to be closely attached to boron atoms. It is noted here that the longer bond length implies a weaker interaction of $\mathrm{B}-\mathrm{H}$ bonds at lower pressures. As a result, the present calculations show that applying pressure can cause changes in the structural and electronic parameters of unit cell, e.g., charge of boron atoms in cation increases slowly with increasing covalency or decreasing ionicity.

\section{Conclusions}

In conclusion, electro-optical properties, possible decomposition reaction pathways and pressure-dependent properties of an Al-Li-tetrahydroborate, $\mathrm{Al}_{3} \mathrm{Li}_{4}\left(\mathrm{BH}_{4}\right)_{13}$, have been investigated using a first-principle plane-wave pseudopotential method. Calculated structural parameters of the compound agree well with the previously reported experimental and other theoretical results. However, calculated electronic structure results show that $\mathrm{Li}$ and $\mathrm{Al}$ atoms are very electropositive; on the contrary, B atoms are very electronegative in the structure. In the possible decomposition reaction pathways, the constituent $\mathrm{Li}-\mathrm{Al}$ tetraborohydride obeys the stability criteria and at the ambient temperature the system does not have long time in cubic symmetry, which has already been observed experimentally [34]. In this study, two possible decomposition reactions of $\mathrm{Al}_{3} \mathrm{Li}_{4}\left(\mathrm{BH}_{4}\right)_{13}$ were proposed; 18 hydrogen molecules are released in the first reaction $\left(27 / 2\right.$ of them from diborane $\left.\left(\mathrm{B}_{2} \mathrm{H}_{6}\right)\right)$, totally about $12.03 \mathrm{wt} \%$, and in the second reaction it is larger, 24 hydrogen molecules or about $16.04 \mathrm{wt} \%$. On the other hand, our calculated photon excitation results lend further support to the assignment of two individual units in the structure, such as anions and cations. The interband transitions between occupied and unoccupied bands support the relation between electronic DOSs and complex dielectric function.

In the last step, the pressure-dependent properties of $\mathrm{Al}_{3} \mathrm{Li}_{4}\left(\mathrm{BH}_{4}\right)_{13}$ have been investigated in the range of 0 $50 \mathrm{GPa}$ hydrostatic pressure. With increasing pressure on the structure, the lattice parameter, the volume of unit cell, the quasiparticle band gap and also enthalpy of the system decrease nearly monotonically; therefore, the acceptor levels gradually get filled and the Fermi level shifts upwards. Decreasing pseudo-band gap shows that $\mathrm{Al}_{3} \mathrm{Li}_{4}\left(\mathrm{BH}_{4}\right)_{13}$ becomes less dielectric when the pressure increases. A relation was also obtained between the Fermi level and a small change of volume ratio in the low pressure range for Zintl phases, which is a compound class bridging metallic, ionic and covalent substances. These behaviours continue throughout; the amount of charge transfer increases with increasing pressure; however, boron atoms become negatively charged (as acceptor) at all pressures and each hydrogen atom appears to be closely attached to boron atoms. For example, arising from the Mulliken bond populations, while the cation $\left(\left[\mathrm{Li}_{4}\left(\mathrm{BH}_{4}\right)\right]^{3+}\right)$ has totally about $+4.4|\mathrm{e}|$ charge at $0 \mathrm{GPa}$, the same cation has totally $+5.92|\mathrm{e}|$ charge at $50 \mathrm{GPa}$. In this range, as a function of pressure the Mulliken bond population of $\mathrm{B}-\mathrm{H}$ bonds increases, whereas bond length decreases. Consistently, the charge of boron atoms in cation increases slowly with increasing covalency or decreasing ionicity.

As a result, our study would help clarify electro-optical characteristics, the stability criteria of possible decomposition reactions and pressure-dependent structural and charge transfer properties of $\mathrm{Al}_{3} \mathrm{Li}_{4}\left(\mathrm{BH}_{4}\right)_{13}$. We hope that these results would lead to a deeper understanding of the new potential hydrogen storage materials such as double-cation tetrahydroborates.

\section{Acknowledgements}

I would like to thank Professor B Inem, Head of Mechanical Metallurgy Section of Metallurgy and Materials Engineering Department of Gazi University, for carefully reading and commenting on the manuscript.

\section{References}

[1] Sheffield W and Sheffield C (eds) 2007 NATO science for peace and security series $C$ (Dordrecht, Netherlands: Springer) 
[2] Ricci M, Bellaby P and Flynn R 2008 Int. J. Hydrogen Energy 335868

[3] Murphy J D and Thamsirirroj T 2011 Mater. Today 14518

[4] Goltsov V A and Veziroglu T N 2001 Int. J. Hydrogen Energy 26909

[5] Chen P and Zhu M 2008 Mater. Today 1136

[6] Veziroğlu T N 2000 Int. J. Hydrogen Energy 251143

[7] Website: http://www.doe.gov

[8] Sakintuna B, Lamari-Darkrim F and Hirscher M 2007 Int. J. Hydrogen Energy 321121

[9] Orimo S I, Nakamori Y, Eliseo J R, Züttel A and Jensen C M 2007 Chem. Rev. 1074111

[10] Züttel A, Borgschulte A and Schlapbach L (eds) 2008 Hydrogen as a future energy carrier (Weinheim: Wiley-VCH)

[11] Wang P and Kang X D 2008 Dalton Trans. 405400

[12] George L, Drozd V, Saxena S K, Bardaji E G and Fichtner M J 2009 Phys. Chem. C 113486

[13] Grochala W and Edwards P P 2004 Chem. Rev. 1041283

[14] Filinchuk Y, Nevidomskyy A H, Chernyshov D and Dmitriev V 2009 Phys. Rev. B 79214111

[15] Jepsen L H, Ley M B, Lee Y-S, Cho Y W, Dornheim M, Jensen J O et al 2014 Mater. Today 17129

[16] Filinchuk Y, Chernyshov D, Nevidomskyy A H and Dmitriev V 2008 Angew. Chem. Int. Ed. 47529

[17] Züttel A, Borgschulte A and Orimo S I 2007 Scr. Mater. 56 823

[18] Tekin A, Caputo R and Züttel A 2010 Phys. Rev. Lett. 104 215501

[19] Ravnsbæk D B and Jensen T R 2012 J. Appl. Phys. 111112621

[20] Nakamori Y, Miwa K, Ninomiya A, Li H, Ohba N, Towata S et al 2006 Phys. Rev. B 74045126

[21] Filinchuk Y, Nevidomskyy A H, Chernyshov D and Dmitriev V 2009 Phys. Rev. B 79214111

[22] Bardaji E G, Zhao-Karger Z, Boucharat N, Nale A, van Setten M J, Lohstroh W et al 2011 Phys. Chem. C 1156095

[23] Hummelshøj J S et al 2009 J. Chem. Phys. 131014101

[24] Li H-W, Orimoa S, Nakamori Y, Miwa K, Ohba N, Towata S et al 2007 J. Alloys Compd. 446-447 315

[25] Nickels E A, Jones M O, David W I F, Johnson S R, Lowton R L, Sommariva M et al 2008 Angew. Chem. Int. Ed. Engl. 47 2817

[26] Ravnsbæk D B, Filinchuk Y, Cerenius Y, Jakobsen H J, Besenbacher F, Skibsted J et al 2009 Angew. Chem. Int. Ed. 486659

[27] Xiao X B, Yu W Y and Tang B Y 2008 J. Phys.: Condens. Matter 20445210

[28] Hagemann H, Longhini M, Kaminski J W, Wesolowski T A, Cerny R, Penin N et al 2008 J. Phys. Chem. A 1127551

[29] Cerny R, Severa G, Ravnsbak D, Filinchuk Y, Anna V D, Hagemann H et al 2010 J. Phys. Chem. C 1141357

[30] Cerny R, Chul K Ki, Penin N, Anna V D, Hagemann H and Sholl D S 2010 J. Phys. Chem. C 11419127

[31] Knight D A, Zidan R, Lascola R, Mohtadi R, Ling C, Sivasubramanian P et al 2013 J. Phys. Chem. C 11719905

[32] Jaron T, Orlowski P A, Wegner W, Fijałkowski K J, Leszczyn P J, Leszczyński P J et al 2015 Angew. Chem. 1271252

[33] Cerny R, Ravnsbæk D, Severa G, Filinchuk Y, Anna V D, Hagemann H et al 2010 Phys. Chem. C 11419540
[34] Lindemann I, Ferrer R D, Dunsch L, Filinchuk Y, Cerny R, Hagemann H et al 2010 Chem. Eur. J. 168707

[35] Lindemann I, Ferrer R D, Dunsch L, Cerny R, Hagemann H, Anna V D et al 2011 Faraday Discuss. 151231

[36] Jaroń T and Grochala W 2011 Dalton Trans. 4012808

[37] Sun W, Chen X, Gu Q, Wallwork K S, Tan Y, Tang Z et al 2012 Chem. Eur. J. 186825

[38] Schouwink P, Anna V D, Ley M B, Lawson Daku L M, Richter B, Jensen T R et al 2012 J. Phys. Chem. C 11610829

[39] Cerny R, Schouwink P, Sadikin Y, Stare K, Smrcok L, Richter B et al 2013 Inorg. Chem. 529941

[40] Liu Y, Zhou J and Jena P 2015 J. Phys. Chem. C 11911056

[41] Ravnsbæk D B, Sørensen L H, Filinchuk Y, Besenbacher F and Jensen T R 2012 Angew. Chem. Int. Ed. 513582

[42] Gradisek A, Ravnsbæk D B, Vrtnik S, Kocjan A, Lužnik J, Apih T et al 2013 J. Phys. Chem. C 11721139

[43] www.physics.metu.edu.tr/erkoc2013/sunumlar/09-Mehmet_ Simsek.pdf. Structural properties of the Al-Li-borohydrides were presented at the conference dedicated to Professor Sakir Erkoc from METU, on the occasion of his 65th birthday: 7th October 2013, METU, Ankara/Turkey

[44] Lindemann I, Borgschulte A, Callini E, Züttel A, Schultz L and Gutfleisch O 2013 Int. J. Hydrogen Energy 382790

[45] Clark S J, Segall M D, Pickard C J, Hasnip P J, Probert M J, Refson K et al 2005 Z. Kristallogr. 220567

[46] Wanderbilt D 1990 Phys. Rev. B 417892

[47] Hammer B, Hansen L B and Norskov J K 1999 Phys. Rev. B 597413

[48] Fischer T H and Almlof J 1992 J. Phys. Chem. 969768

[49] Alouani M and Wills J M 1996 Phys. Rev. B 542480

[50] Li M F 1991 Physics of semiconductors (Beijing: Science Press)

[51] Blonski P and Lodziana Z 2014 Phys. Rev. B 90054114

[52] Downs A J and Jones A 1994 Polyhedron 132401

[53] Kang X-D, Wang P, Ma L P and Cheng H M 2007 Appl. Phys. A 89963

[54] Dovgaliuk I, Ban V, Sadikin Y, Cerny R, Aranda L, Casati N et al 2014 J. Phys. Chem. C 118145

[55] Schlesinger H I, Sanderson R T and Burg A B $1940 \mathrm{~J}$. Am. Chem. Soc. 623421

[56] Beach J Y and Bauer S H 1940 J. Am. Chem. Soc. 623440

[57] Guo Y, Yu X, Sun W, Sun D and Yang W 2011 Angew. Chem. 1231119

[58] Weast R C and Astle M J (eds) 1982 CRC handbook of chemistry and physics, 63rd edn (Florida, USA: CRC Press)

[59] Chong M, Callini E, Borgschulte A, Züttel A and Jensen C M 2014 RSC Adv. 463933

[60] Mulliken R S 1955 J. Chem. Phys. 232343

[61] De A and Pryor C E 2012 Phys. Rev. B 85125201

[62] Bouhemadou A and Khenata R 2007 Comput. Mater. Sci. 39 803

[63] Vasvari B 1968 Rev. Mod. Phys. 40776

[64] Wang F and Miller G J 2011 Inorg. Chem. 507625

[65] Sevov S C 2002 (eds) J H Westbrook and R L Freisher Zintl phases in intermetallic compounds, principles and practice: progress (Chichester, England: John Wiley \& Sons. Ltd.) p 113 